\title{
Metabolic reprogramming-based characterization of circulating tumor cells in prostate cancer
}

Jing Chen ${ }^{1,2}$, Shunwang Cao ${ }^{1}$, Bo Situ' ${ }^{1}$ Juan Zhong ${ }^{3}$, Yanwei $\mathrm{Hu}^{1}$, Shufen $\mathrm{Li}^{1}$, Jinlan Huang ${ }^{4}$, Jiasen Xu ${ }^{5}$, Shiyang $\mathrm{Wu}^{5}$, Jinduan Lin ${ }^{1}$, Qianwen Zhao ${ }^{1}$, Zhen Cai ${ }^{1 *}$, Lei Zheng ${ }^{1,2^{*}}$ and Qian Wang ${ }^{1,6^{*}}$

\begin{abstract}
Background: Circulating tumor cells (CTCS), an advantageous target of liquid biopsy, is an important biomarker for the prognosis and monitoring of cancer. Currently, detection techniques for CTCs are mainly based on the physical and/or epithelial characteristics of tumor cells. However, biofunctional activity markers that can indicate the high metastatic capacity of CTCs are lacking.

Methods: Functional microarray, quantitative real-time polymerase chain reaction, and Western blot were used on five prostate cancer cell lines with different metastatic capacities to identify the metastasis-related metabolic genes. The identified genes were detected in the CTCs of 64 clinical samples using the RNA in situ hybridization. A multi-criteria weighted model was used to determine the optimal metabolic markers for the CTCs test. Based on five fluorescent signals targeting DAPI, CD45, metabolic, epithelial (EpCAM/CKs), and mesenchymal (Vimentin/Twist) markers, the filtration-enriched CTCs were classified as $\mathrm{GM}^{+} \mathrm{CTCs} / \mathrm{GM}^{-} \mathrm{CTCs}$ (metabolic types) or E-CTCs/H-CTCS/M-CTCs (EMT types). Correlation analysis and ROC curve were conducted on 54 prostate cancer samples to evaluate the clinical significance of CTCs subtypes.

Results: Eight metastasis-related metabolic genes were identified, including HK2, PDP2, G6PD, PGK1, PHKA1, PYGL, PDK1, and PKM2. Among them, PGK1 and G6PD were determined as optimal glucose metabolic (GM) markers for CTCs. GM ${ }^{+}$CTCs (marked by PGK1/G6PD) were detectable in 64.8\% (35/54) of prostate cancer patients, accounting for 46.5\% (134/288) of total CTCs. An increased $\mathrm{GM}^{+} \mathrm{CTC}$ level was associated with advanced tumor stage and metastasis $(P<0.05)$. In the discrimination of cancer metastasis from non-metastasis, $\mathrm{GM}^{+} \mathrm{CTC}$ presented a higher AUC of the ROC curve (0.780) compared with the EMT CTCs subtypes (E-CTCs 0.729, H-CTCs 0.741, and M-CTCs 0.648). A triple tPSA-Gleason-GM+ ${ }^{+} \mathrm{CTC}$ marker increased the AUC to 0.904, which was better than that of the tPSA-Gleason-H-CTCs marker (0.874).

Conclusions: The metabolic marker (PGK1/G6PD) is determined as the indicator for the biofunctional activity analysis of CTCS, compared with the existing morphological (EMT) classification on CTCs. The metabolic characterization of CTCs demonstrates that hypermetabolic $\mathrm{GM}^{+} \mathrm{CTCs}$ are promising biomarkers for prostate cancer metastasis.
\end{abstract}

Keywords: Circulating tumor cells, Metabolic reprogramming, Cancer metastasis biomarker

\footnotetext{
* Correspondence: jean_cz@yeah.net; nfyyzl@163.com;

nfyywangqian@163.com

${ }^{1}$ Laboratory Medicine Center, Nanfang Hospital, Southern Medical University,

1838 North of Guangzhou Avenue, Guangzhou 510515, Guangdong, China

Full list of author information is available at the end of the article
}

(c) The Author(s). 2018 Open Access This article is distributed under the terms of the Creative Commons Attribution 4.0 International License (http://creativecommons.org/licenses/by/4.0/), which permits unrestricted use, distribution, and reproduction in any medium, provided you give appropriate credit to the original author(s) and the source, provide a link to the Creative Commons license, and indicate if changes were made. The Creative Commons Public Domain Dedication waiver (http://creativecommons.org/publicdomain/zero/1.0/) applies to the data made available in this article, unless otherwise stated. 


\section{Background}

Circulating tumor cells (CTCs) are tumor cells derived from the tumor origin or metastasis and released into the bloodstream. The dissemination and tumorigenicity of CTCs $[1,2]$ indicate that they are important seeds for tumor metastasis, which is the leading cause of poor prognosis in cancer patients. Compared with traditional tissue biopsy, CTCs detection helps make possible non-invasive screening and monitoring of cancer. Recent studies have demonstrated the expanding roles of CTCs counts in the prognosis of breast, colorectal, lung, and prostate cancers [3-5]. However, merely detecting the number of CTCs has limited benefit for clinical interpretation when inter- and intra-tumor heterogeneities are considered $[6,7]$. Further exploration of the genetic and phenotypic features of CTCs could provide information on the nature of individual tumor cells, which would be useful for disease evaluation and therapeutic decision-making.

The epithelial-mesenchymal transition (EMT) classification is the most investigated phenotypic characteristic of CTCs in recent years. EMT plays a vital role in tumor metastasis. The epithelial cells gain mesenchymal properties for cell movement via EMT, whereas the disseminated cells might recover epithelial properties for rapid colonization through mesenchymal-epithelial transition (MET) [8]. Hence, CTCs phenotypes might include E-CTCs (epithelial), M-CTCs (mesenchymal), and $\mathrm{H}-\mathrm{CTC}$ (hybrid). Increased H-CTCs and M-CTCs have been reported as more relevant to metastatic potential and aggressive progression [9, 10]. Nevertheless, static morphological analysis may be unsatisfactory for determining the change and outcome of CTCs because of the dynamic variation of EMT and MET [8]. It remains unclear whether all CTCs that present the same plastic EMT phenotype are capable of going through the metastatic cascade to form metastases. Thus, a great need exists for developing biofunctional activity markers to evaluate the actual roles of CTCs in cancer metastasis.

The deregulation of cellular energetics is a hallmark of tumor cells [11] and plays a crucial role in cancer progression by promoting EMT, anoikis resistance, angiogenesis, and cell stemness [12]. Glucose metabolic reprogramming is characterized by active aerobic glycolysis together with enhanced pentose phosphate pathway and glutaminolysis. These processes promote the accumulation of precursor molecules and activation of signaling pathways to modulate cell proliferation and migration [13, 14]. Our previous studies have suggested that tumor cell malignancy is closely associated with metabolic conversion toward a glycolytic pattern [15]. Many research works have also highlighted the decisive effect of metabolic transition on tumor cell behavior [16, 17]. For instance, the pro-metastatic protein S100A4 was reported to stimulate invasiveness in poorly motile melanoma cells by suppressing mitochondrial activity and potentiating glycolysis [16]. PCK2 is a crucial factor for the metabolic switch from oxidative phosphorylation to aerobic glycolysis. Zhao et al. [17] showed that PCK2 knockdown reduced the tumor-initiating ability of prostate cancer ( $\mathrm{PCa}$ ) cells in the in vivo xenograft models and that the increased PCK2 level was associated with more aggressive tumors and lower survival rates for $\mathrm{PCa}$ patients.

Accordingly, it is widely agreed that metabolic reprogramming is a crucial feature of the highly aggressive tumor cells. In the present work, we aim to utilize the metabolic characteristics to establish a functional activity indicator for CTCs, and explore the feasibility and significance of the metabolic markers in CTCs detection.

\section{Methods}

\section{Cell lines and cell culture}

Paired isogenic PCa cell lines PC-3 M 2B4 and PC-3 M $1 \mathrm{E} 8$ which differ in metastatic ability were purchased from the Institute of Basic Medical Sciences (Chinese Academy of Medical Sciences, Beijing, China). LNCAP, PC-3, and DU145 cell lines were bought from the Cell Bank of Type Culture Collection (Chinese Academy of Sciences, Shanghai, China). LNCAP and DU145 cells were maintained in Dulbecco's Modified Eagle Medium (Gibco, Gaithersburg, MD, USA). PC-3 M 2B4, PC-3 M 1E8, and PC-3 cells were maintained in Roswell Park Memorial Institute 1640 Medium (Gibco). Cells were supplemented with $10 \%$ fetal bovine serum (Gibco) and cultured in a humidified incubator $\left(37^{\circ} \mathrm{C}, 5 \% \mathrm{CO}_{2}\right)$.

\section{Wound healing assay}

Cell migration rates were assessed by wound healing assay. Cells were routinely cultured until they reached monolayer confluence. Wounds were created with a $200 \mu \mathrm{L}$ tip (Corning, NY, USA). After washing with phosphate-buffered saline (Gibco), the cells were incubated with fresh serum-free medium for $24 \mathrm{~h}$. The wound widths were measured using an inverted microscope (Olympus CKX41, Tokyo, Japan). The migration rate was calculated as the average wound closure percent of five random fields in three repetitions.

\section{Cell migration and invasion assay}

Cell migration and invasion assays were performed using Transwell chambers (Corning). For the migration assays, $5 \times 10^{4}$ cells suspended in $200 \mu \mathrm{L}$ of serum-free medium were added to the upper chamber and $500 \mu \mathrm{L}$ of medium containing 10\% FBS was added to the lower chamber. After routine incubation for $24 \mathrm{~h}$, the upper chambers were stained with a crystal violet kit (Beyotime, Shanghai, China). Cells outside the upper chamber 
were imaged and counted in five random fields using a microscope (Olympus Bx51, Tokyo, Japan). Similar protocols were performed for the invasion assays, except that $50 \mu \mathrm{L}$ of Matrigel (BD Biosciences, NJ, USA) was added to the upper chamber overnight before the cells were seeded. Each assay was repeated three times.

\section{Microarray analysis}

The gene profiles of PC-3 M 2B4 and PC-3 M 1E8 cells were compared using the Human Glucose Metabolism $\mathrm{RT}^{2}$ Profiler $^{\mathrm{Tm}}$ PCR Array (PAHS-006Z, SuperArray, Frederick MD, USA). RNA isolation and purification were conducted according to the manufacturer's protocol (Qiagen, Hilden, Germany). Qualified RNA was converted to cDNA using the $\mathrm{RT}^{2}$ First Strand Kit (Invitrogen, Carlsbad, CA, USA). The cDNA template was then added to an instrument-specific ready-to-use $\mathrm{RT}^{2}$ SYBR Green qPCR Master Mix (Invitrogen), and the array detection was performed using an ABI PRISM7900 instrument (Applied Biosystems, Foster City, CA, USA). All Ct values were corrected by the average $\mathrm{Ct}$ of a housekeeping gene (ACTB). KangChen Bio-tech Company (Shanghai, China) assisted the analysis.

\section{Quantitative real-time polymerase chain reaction (qRT- PCR) analysis}

Expression of the array-identified genes was verified in all five PCa cells by qRT-PCR. RNA was isolated using RNAiso Reagent (Takara, Dalian, China) according to the manufacturer's instructions. RNA sample $(1 \mu \mathrm{g})$ was used to synthesize the cDNA with a PrimeScript RT reagent kit (Takara). The qRT-PCR reaction mixture was prepared using an SYBR Premix Ex Taq kit (Takara) and detected on an ABI 7500 Fast Real-Time PCR system (Applied Biosystems). The ACTB gene was used as the internal reference. Relative quantification was calculated using the $2^{-\Delta \Delta C t}$ method [18]. Gene expression results were determined as the mean of three independent tests. The information on primers is shown in Additional file 1: Table S1.

\section{Western blot analysis}

Total proteins were extracted from the cultured cells using a Whole Cell Lysis Assay Kit (Keygen, Jiangsu, China) according to the operating instructions. Protein sample $(30 \mu \mathrm{g})$ was separated by $15 \%$ sodium dodecyl sulphate-polyacrylamide gel (Bio-Rad, Gladesville, NSW, Australia) and transferred to polyvinylidene difluoride membranes (Millipore, Billerica, MA, USA). The membranes were then blocked with 5\% non-fat milk for $2 \mathrm{~h}$ and incubated with primary antibodies overnight at $4{ }^{\circ} \mathrm{C}$. After incubation with HRP-labeled secondary antibodies for $1 \mathrm{~h}$ at room temperature, the protein bands were detected using a chemiluminescence HRP kit (Millipore). The ACTB protein was measured as the internal reference for normalization. Experiments were repeated three times. Detailed information on the antibodies is presented in Additional file 2: Table S2.

\section{Patients and samples}

A total of 118 cancer patients were enrolled from Nanfang Hospital, Southern Medical University (Guangzhou, China) in two cohorts from December 2016 to August 2017. Cohort 1 included 64 patients pathologically diagnosed with common cancers (12 hepatocellular carcinoma, 14 lung cancer, 10 nasopharyngeal carcinoma, 9 esophageal cancer, $6 \mathrm{PCa}$, and 13 cervical cancer). Cohort 2 included 54 patients pathologically diagnosed with $\mathrm{PCa}$, of which 29 had metastatic disease and 25 had no metastatic lesions. Patients were eligible if they were over 18 years of age and had no other concurrent tumors; otherwise they were excluded. Blood samples were collected for CTCs analysis from both cohorts before any treatment was provided. Other pathological characteristics were simultaneously determined, including tumor features (Gleason score, stage, and metastasis) and disease-related serum biomarkers such as total prostate-specific antigen (tPSA), alkaline phosphatase (ALP), and Hemoglobin B (Hb).

\section{Ethics approval}

The study methodologies conformed to the standards set by the Declaration of Helsinki. The research protocol was approved by the Ethics Committee of Nanfang Hospital (Approval No. 2016-172), and all patients provided informed consent.

\section{CTCs enrichment and identification}

CTCs isolation and identification were performed on the CanPatrol platform (SurExam, Guangzhou, China) using size-based microfiltration and fluorescence staining, as previously described [19]. Briefly, $5 \mathrm{~mL}$ of blood samples were collected and pre-treated with ammonium chloride-based lysis buffer to remove erythrocytes. The karyocytes were then filtrated with a membrane (Millipore) with calibrated pores (diameter $8 \mu \mathrm{m}$ ). Cell nuclei of the retained cells were stained with 4',6-diamidino-2-phenylindole (DAPI; Sigma, St. Louis, USA) for microscopic scanning (Zeiss, Germany). The leukocytes were excluded using the Alexa Fluor 740-labeled probes targeting CD45. Large cells with an oval or heteromorphic nucleus and specific chromatin but that had no expression of CD45 were identified as CTCs. The cell-counting results were judged as detectable CTCs $(\geq 1 / 5 \mathrm{~mL})$ and positive CTCs $(\geq 3 / 5 \mathrm{~mL})$. The method for determining the positive standard of cell counting is described in Additional file 3: Determination of the positive standard for CTCs counting. 


\section{Detection of metabolic and EMT markers in CTCs}

The multiple RNA in situ hybridization (multi-RNAISH) technique was used to detect the molecular characteristics of the enriched CTCs. Five single channels of the automated imaging microscope were used to detect the fluorescent signals of markers that reflect different characteristics of CTCs. Except for the above-mentioned channels for DAPI $\left(F_{1}\right)$ and $\operatorname{CD} 45\left(F_{2}\right)$, the $F_{3}$ channel was used to detect single or combined glucose metabolic (GM) genes. The capture probes for the previously identified genes were labeled by Alexa Fluor 647 and the probe sequences are shown in Additional file 4: Table S3. The metabolic CTCs phenotype was determined as $\mathrm{GM}^{+} \mathrm{CTCs}$ or $\mathrm{GM}^{-} \mathrm{CTC}$ according to the selected GM markers. The Cy3-labeled epithelial markers (EpCAM and CK8/18/19) and Alexa Fluor 488-labeled mesenchymal markers (Vimentin and Twist) were detected in the $\mathrm{F}_{4}$ and $\mathrm{F}_{5}$ channel. Sequences of the capture probes for these EMT markers were described previously [19]. The EMT phenotype of CTCs was determined as epithelial(E-), hybrid- (H-) or mesenchymal- (M-) type.

\section{Statistical analysis}

Statistical analyses were performed using SPSS 13.0 (SPSS Inc., Chicago, IL, USA). Data were presented as mean \pm SD for continuous variables (cell line assays). Differences between groups were compared using Student's t-test or one-way ANOVA. Discontinuous variables (CTCs parameters) were presented as median with the interquartile range (IQR). Mann-Whitney U or Kruskal-Wallis $\mathrm{H}$ tests were used to compare differences. Categorical variables (clinical data) were expressed as numbers and percentages. The clinical relevance of the CTCs parameters was evaluated using Chi-square and Spearman's rank correlation test. All tests were two-tailed, and a $P$ value $<0.05$ was considered statistically significant.

\section{Results}

Screening and validation of metastasis-related metabolic genes in PCa cell lines

Five PCa cell lines with different metastatic capacities were used to determine the metastatic-related glucose metabolism molecules. PC-3 M 2B4 (2B4) and PC-3 M 1E8 (1E8) are paired isogenic PCa cells with low and high metastatic abilities, both derived from PC-3 M cells [20]. We chose 2B4 and 1E8 cells for the metabolic microarray analysis. To ensure the accuracy of the following experiment, we verified the metastatic ability of these cells with wound healing and Transwell assays. The wound closure rate of $1 \mathrm{E} 8$ cells was $(50.4 \% \pm 8.81)$ at $24 \mathrm{~h}$, which was much higher than that of $2 \mathrm{~B} 4$ cells $(24.1 \% \pm 4.14)$. The migration and invasion numbers of 2B4 cells were $(108 \pm 11.2)$ and $(78 \pm 9.63)$, whereas the numbers for 1E8 cells were markedly higher at (345 \pm
12.3) and $(179 \pm 11.7)(P<0.001$; Additional file 5: Figure S1A and B). These data verified that 1E8 cells had much higher metastatic ability than 2B4 cells, at least in vitro. LNCAP, PC-3, and DU145 cells are common PCa cells derived from PCa patients with lymphatic-, bone-, and brain-metastases, respectively [21-23]. The wound healing and Transwell assays showed that they had different metastatic capacities. The metastatic abilities of LNCAP, PC-3, and DU145 cells ranked low to high $(P<$ 0.001; Additional file 5: Figure S1C and D). They were therefore used to validate the array results.

The Human Glucose Metabolism Array profiles 84 key genes involved in glucose and glycogen metabolism (Additional file 6: Table S4). We used this array to compare the metabolic genes of the low metastatic 2B4 and high metastatic 1E8 cells (Fig. 1a). Screening by change fold $>1.5$ and $P<0.05$, the array identified 45 metabolic genes that were up-regulated in $1 \mathrm{E} 8$ cells compared with 2B4 cells (Fig. 1b). The qRT-PCR assays verified the difference of the mRNA levels of these genes in the two cells, whereas the Western blot assays showed inconsistent results of the protein levels of some genes (Fig. 1c-e). The mRNA levels of HK2, PDP2, G6PD, and PYGL were significantly higher in the 1E8 cells than that in the 2B4 cells $(P<$ 0.05 ), and the mRNA levels of PKM2 were similar in both cells (Fig. 1c). Nonetheless, the protein levels of HK2, PDP2, G6PD, and PYGL were similar in the two cells, and the protein level of PKM2 was significantly higher in the $1 \mathrm{E} 8$ cells than that in the 2B4 cells (Fig. 1e). In the comparison of LNCAP, PC-3, and DU145 cells, however, both the mRNA and protein levels of the selected genes were verified as up-regulated in the high metastatic cells (DU145) than that in the low metastatic cells (LNCAP and PC-3) $(P<0.05$; Fig. $1 \mathrm{~d}$ and e). Combining the literature review and these results, eight genes were further validated as showing increased mRNA expression related to the high metastatic capacity, which could be enrolled as candidates for the next assessment. These genes were HK2 (Hexokinase 2), PDP2 (Pyruvate dehydrogenase phosphatase catalytic subunit 2), G6PD (Glucose-6-phosphate dehydrogenase), PGK1 (Phosphoglycerate kinase 1), PHKA1 (Phosphorylase kinase alpha 1), PYGL (Phosphorylase-glycogen liver), PDK1 (Pyruvate dehydrogenase kinase 1), and PKM2 (Pyruvate kinase-muscle 2). Their functions in glucose metabolism are presented in Additional file 7: Figure S2. Among them, HK2, PGK1, and PKM2 participate in the transformation of glucose to pyruvate in glycolysis. G6PD catalyzes glucose-6-phosphatase to generate ribose-5-phosphate, which is the key process of the pentose phosphate pathway. PDK1 and PDP2 regulate the reaction from pyruvate to Acetyl-CoA in the 

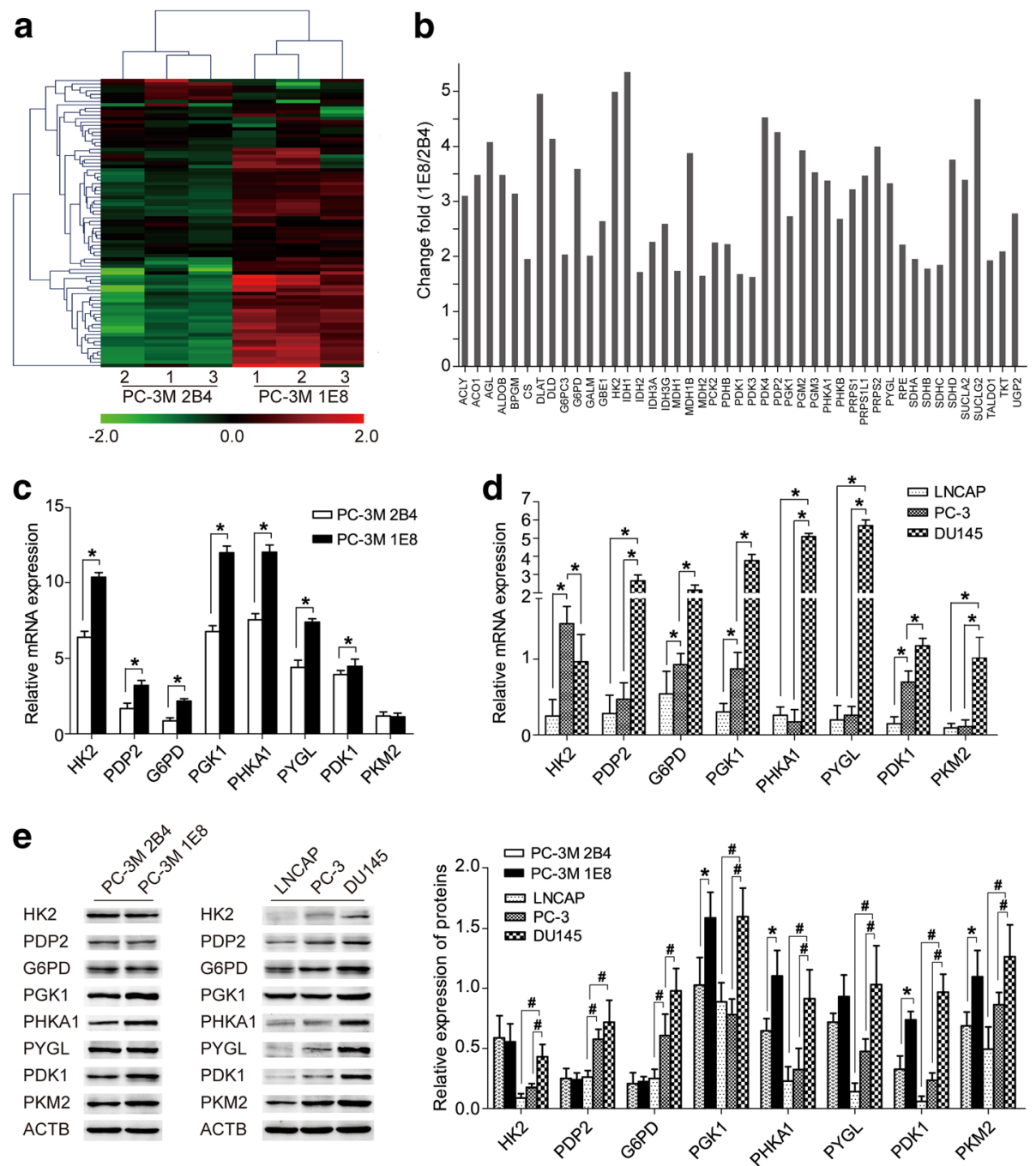

Fig. 1 Screening and validation of metastasis-related metabolic genes in PCa cell lines. a Hierarchical clustering analysis of the metabolic gene profiles between $2 \mathrm{~B} 4$ and 1E8 cells in the functional microarray assay. $\mathbf{b}$ The array identified genes that were up-regulated in $1 \mathrm{E} 8$ cells compared with 2 B4 cells (change fold $>1.5$ and $P<0.05$ ). $\mathbf{c}-\mathbf{d}$ Relative mRNA levels of the differentially expressed metabolic genes in $\mathbf{c} 2 \mathrm{~B} 4$ and $1 \mathrm{E} 8$ cells, and $\mathbf{d}$ LNCAP, PC-3, and DU145 cells by qRT-PCR test, including HK2, PDP2, G6PD, PGK1, PHKA1, PYGL, PDK1, and PKM2 ( $\left.{ }^{*} P<0.05\right)$. e Protein levels of the metabolic genes in all five PCa cells by Western blot and quantitative analysis ( ${ }^{*} P<0.05$ between 1 E8 and $2 B 4 ;{ }^{~} P<0.05$ among LNCAP, PC3, and DU145)

tricarboxylic acid cycle. PYGL and PHKA1 are involved in glycogen degradation as the enzyme and regulator, respectively.

PGK1 and G6PD as combined markers for the metabolic characterization of CTCs

To determine whether the changes of the metabolic genes in CTCs are in consistent with those in the cell lines, we synthesized fluorescent-labeled RNA probes for the above-identified metabolic genes to pre-test their mRNA expression in isolated CTCs. Among 64 patients diagnosed with common cancers (Cohort 1), 40 patients had positive CTCs according to the positive diagnostic criteria ( $\geq 3 \mathrm{CTCs} / 5 \mathrm{~mL}$ ). The 40 positive samples were randomly and evenly divided into 8 groups for the detection of HK2, PDP2, G6PD, PGK1, PHKA1, PYGL, PDK1, and PKM2 in CTCs. We isolated and analyzed a total of 436 CTCs. The expression rates of the eight metabolic genes in CTCs were different (Table 1). Only $16 \%(4 / 25)$ of the CTCs expressed HK2, whereas PDP2, PYGL, and PKM2 were detected in most CTCs, presenting a percentage of $77 \%$ (30/39), 75\% (44/59), and 76\% (68/90), respectively. Furthermore, we assessed the mRNA expression of the metabolic genes in CTCs with different EMT subtypes. There were 77 E-CTCs, 226 $\mathrm{H}-\mathrm{CTCs}$, and $133 \mathrm{M}$-CTCs, respectively. The mRNA expression of the eight metabolic genes varied in CTCs EMT subtypes (Fig. 2a). Significant correlations were 
Table 1 The mRNA expressions of glucose metabolic markers in three EMT types of CTCs (Cohort $1^{\mathrm{a}}$ )

\begin{tabular}{llllllll}
\hline $\begin{array}{l}\text { Target } \\
\text { probe }\end{array}$ & $\begin{array}{l}\text { Positive/ } \\
\text { total CTCS }\end{array}$ & \multicolumn{2}{l}{ Positive/Negative in 3 types } & \multirow{2}{*}{$X^{2}$} & $P$ \\
\cline { 3 - 5 } & E-CTCs & H-CTCs & M-CTCS & & \\
\hline HK2 & $4 / 25(0.16)$ & $0 / 9$ & $4 / 4$ & $0 / 8$ & 7.595 & $0.011^{*}$ \\
PDP2 & $30 / 39(0.77)$ & $4 / 2$ & $21 / 2$ & $5 / 5$ & 7.045 & $0.030^{*}$ \\
G6PD & $37 / 50(0.74)$ & $2 / 0$ & $25 / 1$ & $10 / 12$ & 16.41 & $0.001^{*}$ \\
PGK1 & $25 / 61(0.41)$ & $1 / 6$ & $15 / 26$ & $9 / 4$ & 6.929 & $0.031^{*}$ \\
PHKA1 & $28 / 42(0.67)$ & $7 / 4$ & $17 / 2$ & $4 / 8$ & 10.98 & $0.004^{*}$ \\
PYGL & $44 / 59(0.75)$ & $5 / 5$ & $27 / 8$ & $12 / 2$ & 3.925 & 0.141 \\
PDK1 & $45 / 70(0.64)$ & $5 / 9$ & $23 / 11$ & $17 / 5$ & 6.761 & $0.034^{*}$ \\
PKM2 & $68 / 90(0.76)$ & $16 / 2$ & $36 / 4$ & $16 / 16$ & 17.18 & $0.001^{*}$ \\
\hline${ }^{*} P<0.05$ & & & & & &
\end{tabular}

${ }^{\text {a Cohort }} 1$ includes 64 patients pathologically diagnosed with common cancer presented between the EMT phenotypes of CTCs and mRNA expression of the metabolic genes $(P<0.05)$ except PYGL $(P=0.141)$ (Table 1$)$.

These differences prompted us to further determine the optimal markers for CTCs metabolic profiling. The analytic hierarchy process (AHP) is a common method of multi-criteria decision analysis, in which a hierarchical system is designed to calculate the relative weights of the criteria and assess the project candidates [24, 25]. Here, we established an AHP-based weighted model for the above metabolic genes (Fig. 2b). The evaluation criteria included the expression levels revealed by microarray, cell validation results, positive expression rates in CTCs, correlations with the EMT phenotypes of CTCs and metastasis-related functions reported by literature. The weighting coefficients of these criteria

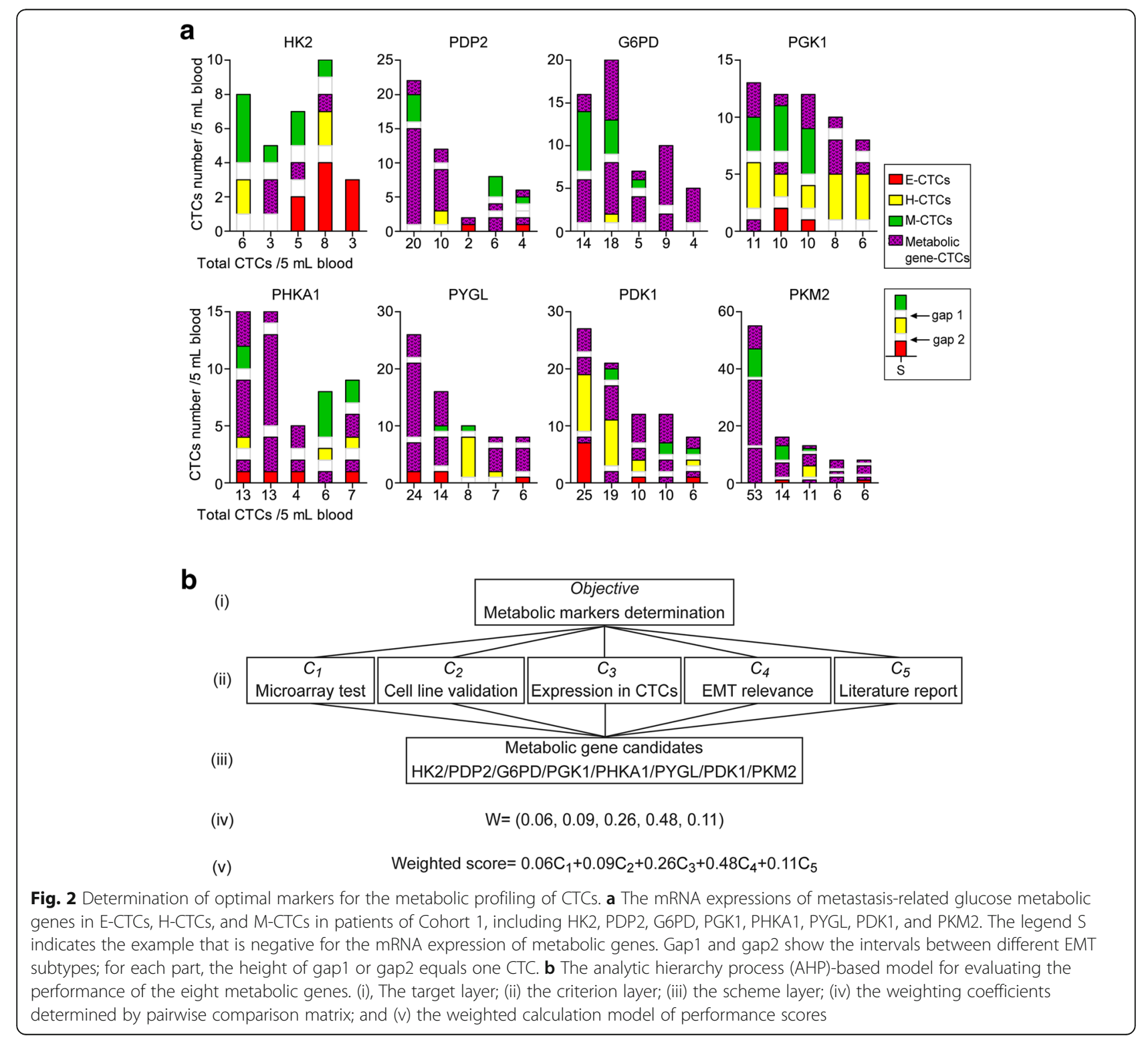


were determined as $0.06,0.09,0.26,0.48$, and 0.11 by a pairwise comparison matrix (Additional file 8: Figure S3). The weighted performance scores of the eight candidates were calculated as 4.44-7.81 according to this model (Additional file 9: Table S5). PGK1 and G6PD, key enzymes involved in the metabolism of glycolysis and the pentose phosphate pathway, had the highest scores of 7.58 and 7.81, respectively. Therefore, we determined PGK1 and G6PD to be optimal markers to characterize the glucose metabolism of CTCs.

\section{Metabolic characterizations of CTCs in the peripheral blood of PCa patients}

Bone metastasis is common in the newly diagnosed $\mathrm{PCa}$ patients even those with early stage tumors. Based on the selected PGK1 and G6PD, we collected the blood samples of 54 pathologically diagnosed $\mathrm{PCa}$ patients (Cohort 2) to test the metabolic features of CTCs. The patients were aged 48-86 years, among which 25 were non-metastatic and 29 were metastatic. Table 2 summarizes other clinical data, including age, Gleason score, clinical stage, and serum disease markers (tPSA, Hb, and ALP). We synthesized Alexa Fluor 647-labeled probes for PGK1 and G6PD (GM markers) to classify the isolated CTCs as $\mathrm{GM}^{+} \mathrm{CTCs}$ and $\mathrm{GM}^{-} \mathrm{CTCs}$ (Fig. 3a). Among the 54 patients, 45 patients (83.3\%) presented detectable CTCs $(\geq 1 / 5 \mathrm{~mL})$, with a range of $1-33 / 5 \mathrm{~mL}$. $\mathrm{GM}^{+} \mathrm{CTC}$ were detectable in $64.8 \%$ $(35 / 54)$ of patients, ranging from 1 to $19 / 5 \mathrm{~mL}$. The patients with positive $(\geq 3 / 5 \mathrm{~mL})$ total CTCs and $\mathrm{GM}^{+} \mathrm{CTCs}$ accounted for $55.6 \%(30 / 54)$ and $31.5 \%(17 / 54)$ of the cohort, respectively.

Moreover, we investigated the correlations between the CTCs parameters $\left(\mathrm{GM}^{+} \mathrm{CTCs}\right.$ or total CTCs) and clinical characteristics of PCa patients (Table 2). In the early stage $(\mathrm{I}+\mathrm{II})$ group, the median $\mathrm{GM}^{+} \mathrm{CTCs}$ was 0 (IQR: $\left.0,1.75\right) /$ $5 \mathrm{~mL}$ and $8.3 \%$ of patients had positive $(\geq 3 / 5 \mathrm{~mL})$ $\mathrm{GM}^{+} \mathrm{CTCs}$; whereas in advanced stage (III + IV) group, the

Table 2 Clinical characteristics of PCa patients (Cohort 2) and the correlation with $\mathrm{GM}^{+} \mathrm{CTCS}$ and total CTCS

\begin{tabular}{|c|c|c|c|c|c|c|}
\hline \multicolumn{3}{|c|}{ Clinical characteristics } & \multicolumn{2}{|c|}{$\mathrm{GM}^{+} \mathrm{CTCS}$} & \multicolumn{2}{|c|}{ Total CTCs } \\
\hline Subgroup & Range & n (Percentage) & $\mathrm{P} / \mathrm{N}^{\mathrm{b}}$ & $P$ & $\mathrm{P} / \mathrm{N}$ & $P$ \\
\hline Age (years) & $48-86$ & & & 0.770 & & $>0.999$ \\
\hline$\leq 70$ & & $27(50.0 \%)$ & $9 / 18$ & & $15 / 12$ & \\
\hline$>70$ & & 27 (50.0\%) & $8 / 19$ & & $15 / 12$ & \\
\hline Gleason score & $6-9$ & & & 0.099 & & $0.013^{*}$ \\
\hline$\leq 7$ & & 28 (51.9\%) & $6 / 22$ & & $11 / 17$ & \\
\hline$\geq 8$ & & $26(48.1 \%)$ & $11 / 15$ & & $19 / 7$ & \\
\hline Clinical Stage & NA & & & $0.003^{*}$ & & $<0.001^{*}$ \\
\hline $\mid+\|$ & & $24(44.4 \%)$ & $2 / 22$ & & $7 / 17$ & \\
\hline III + IV & & $30(55.6 \%)$ & $15 / 15$ & & $23 / 7$ & \\
\hline Metastasis & NA & & & $0.002^{*}$ & & $0.007^{*}$ \\
\hline No & & $25(46.3 \%)$ & $2 / 23$ & & $9 / 16$ & \\
\hline Yes & & $29(53.7 \%)$ & $15 / 14$ & & $21 / 8$ & \\
\hline tPSA $(n g / m L)$ & $0.01-6000.0$ & & & $0.003^{*}$ & & $0.017^{*}$ \\
\hline$\leq 20$ & & $24(44.4 \%)$ & $2 / 22$ & & $9 / 15$ & \\
\hline$>20$ & & $30(55.6 \%)$ & $15 / 15$ & & $21 / 9$ & \\
\hline fPSA/tPSA & $2.24-50.68$ & & & 0.965 & & 0.322 \\
\hline$\leq 15 \%$ & & $32(59.3 \%)$ & $10 / 22$ & & $16 / 16$ & \\
\hline$>15 \%$ & & $22(40.7 \%)$ & $7 / 15$ & & $14 / 8$ & \\
\hline ALP (U/L) & $44-718$ & & & 0.200 & & 0.808 \\
\hline$\leq 90$ & & $26(48.1 \%)$ & $6 / 20$ & & $14 / 12$ & \\
\hline$>90$ & & $28(51.9 \%)$ & $11 / 17$ & & $16 / 12$ & \\
\hline $\mathrm{Hb}(\mathrm{g} / \mathrm{L})$ & $71-162$ & & & 0.507 & & 0.625 \\
\hline$\leq 120$ & & $25(46.3 \%)$ & $9 / 16$ & & $13 / 12$ & \\
\hline$>120$ & & $29(53.7 \%)$ & $8 / 21$ & & $17 / 12$ & \\
\hline
\end{tabular}



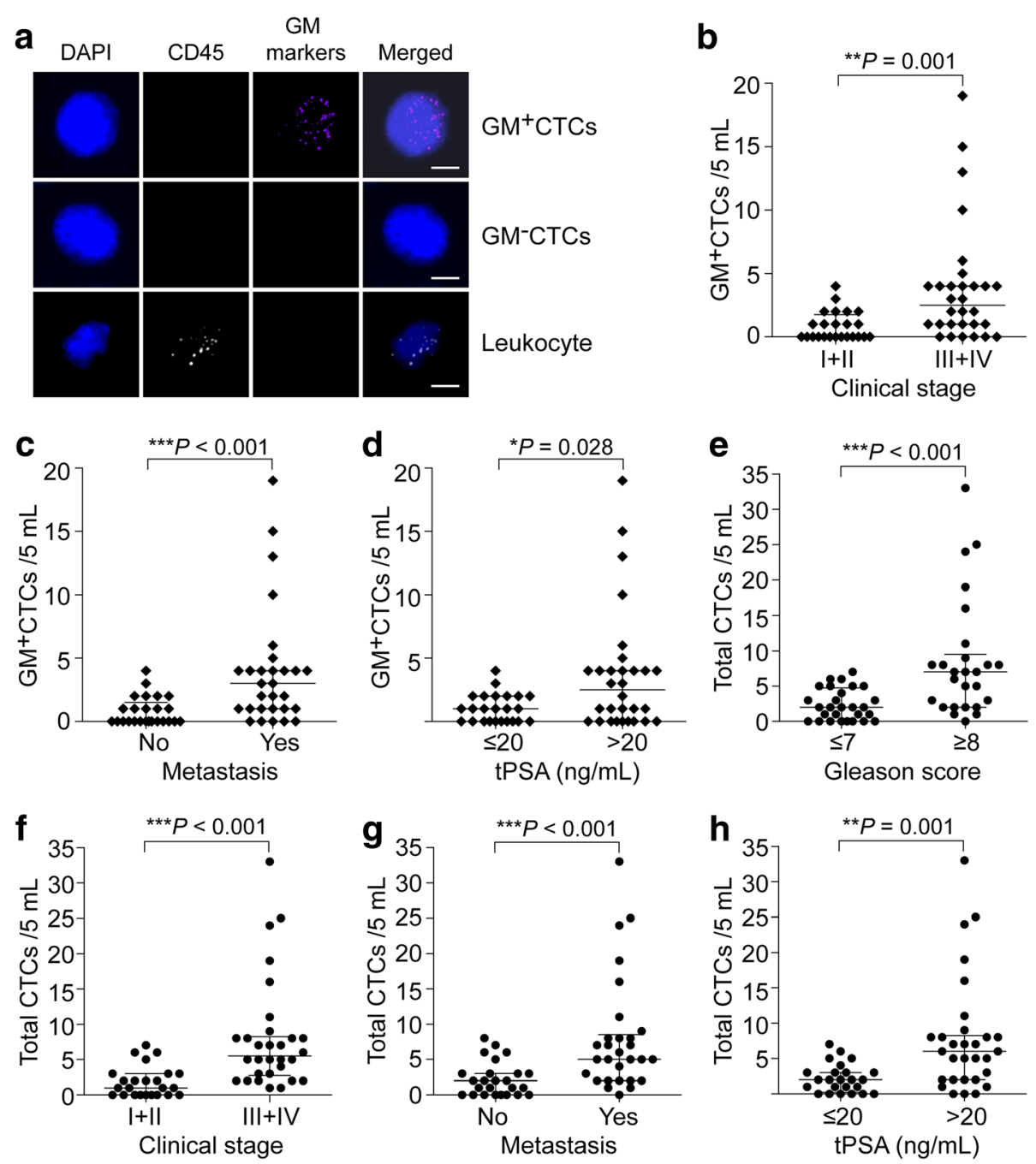

Fig. 3 Metabolic characterizations on CTCs in the peripheral blood of PCa patients. a Images of multi-fluorescence signals representing the leukocyte marker (CD45) and glucose metabolic markers (GM markers: PGK1 and G6PD). The merged pattern shows the images of GM+CTCs, $\mathrm{GM}^{-} \mathrm{CTCS}$, and leukocyte. Scale bar $=5 \mu \mathrm{m}$. b-d Comparison of the $\mathrm{GM}^{+} \mathrm{CTC}$ numbers between the PCa patients in different subgroups of clinical characteristics, including the clinical stage (b), cancer metastasis (c), and serum tPSA level (d). e-h Comparison of the total CTCs numbers between the PCa patients in different subgroups of clinical characteristics, including the Gleason score (e), clinical stage (f), cancer metastasis $(\mathbf{g})$, and serum tPSA level (h). ${ }^{*} P<0.05,{ }^{* * *} P<0.01,{ }^{* * *} P<0.001$

median and positive rates of $\mathrm{GM}^{+} \mathrm{CTCs}$ were higher at 2.5 (IQR: 1,4$) / 5 \mathrm{~mL}$ and $50.0 \%(P<0.01$; Fig. $3 \mathrm{~b}$ and Table 2$)$. The median $\mathrm{GM}^{+} \mathrm{CTCs}$ number in non-metastatic and metastatic patients were 0 (IQR: $0,1.75) / 5 \mathrm{~mL}$ and 3 (IQR: 1,4$) / 5 \mathrm{~mL}(P<0.001$; Fig. 3c). The positive rate of $\mathrm{GM}^{+} \mathrm{CTCs}$ was significantly higher in metastatic patients $(51.7 \%)$ than that in non-metastatic patients (8.0\%) $(P=0.002$; Table 2). We observed similar results in the comparison of tPSA $\leq 20 \mathrm{ng} / \mathrm{mL}$ and tPSA $>20 \mathrm{ng} / \mathrm{mL}$ groups $(P<0.05$; Fig. $3 \mathrm{~d}$ and Table 2$)$. These data revealed that both the number and positive rate of $\mathrm{GM}^{+} \mathrm{CTCs}$ were closely correlated with the clinical stage, metastasis and tPSA level in PCa patients. Likewise, total CTCs level was associated with the higher Gleason score $(\geq 8)$, advanced stage, metastasis and increased tPSA level $(P<0.05$; Fig. $3 \mathrm{e}-\mathrm{h}$ and Table 2). We found no significant correlation between other clinical characteristics (age, serum ALP, and $\mathrm{Hb}$ level) and $\mathrm{GM}^{+} \mathrm{CTCs}$ or total CTCs.

\section{Correlation between the metabolic and EMT phenotypes of CTCs}

Currently, the EMT classification is the most investigated phenotypic analysis of CTCs. The multi-RNA-ISH system could also determine the EMT phenotypes of CTCs based on the E markers (EpCAM and CK8/18/19) and $\mathrm{M}$ markers (Vimentin and Twist). Accordingly, we classified the CTCs of the 54 PCa patients into E-CTCs 
$\left(E^{+} M^{-}\right)$, M-CTCs $\left(E^{-} M^{+}\right)$, and H-CTCs $\left(E^{+} M^{+}\right)$. The clinical relevance analysis revealed that E-CTCs were closely associated with the Gleason score, tumor stage, and tPSA level of patients, whereas H-CTCs were associated with the Gleason score, tumor stage, tPSA level, and cancer metastasis $(P<0.05$; Additional file 10: Table S6). No significant correlation emerged between M-CTCs and these clinical characteristics of the patients.

These results implied us to further evaluate the correlation between the metabolic and EMT phenotypes of CTCs. We analyzed a total of 288 CTCs in the 54 patients, among which the $\mathrm{GM}^{+} \mathrm{CTCs}$ accounted for $46.5 \%$ (134/288). Based on the EMT classification, the E-CTCs, H-CTCs, and M-CTCs accounted for 25.7\% (74/288), $56.9 \%(164 / 288)$, and $17.4 \%(50 / 288)$ of the total CTCs, respectively. The $\mathrm{GM}^{+} \mathrm{CTCs}$ number was closely correlated with the number of H-CTCs $(r=0.807 ; P<0.001)$, whereas we found medium correlations between $\mathrm{GM}^{+} \mathrm{CTCs}$ and E-CTCs $(r=0.369 ; P=0.006)$ or M-CTCs $(r=0.553$; $P$ $<0.001$ ) (Fig. 4a-c). With the multiple channels of a fluorescent microscope, we could further determine each CTC of the three EMT subtypes as $\mathrm{GM}^{+}$or $\mathrm{GM}^{-}$phenotype (Fig. 4d). The proportions of $\mathrm{GM}^{+} \mathrm{CTCs}$ in total E-CTCs,
H-CTCs, and M-CTCs were 24.3\% (18/74), 57.3\% (94/164), and $44.0 \%(22 / 50)$, respectively $(P<0.001$; Fig. 4 e). These data demonstrated that the constituent ratios of $\mathrm{GM}^{+} \mathrm{CTCs}$ and $\mathrm{GM}^{-} \mathrm{CTCs}$ were different among the three EMT subtypes, indicating a remarkable correlation between the metabolic and EMT phenotypes in CTCs.

\section{Metabolic subtypes of CTCs indicate tumor metastasis in PCa patients}

Some reports demonstrated that the total CTCs or mesenchymal CTCs could be indicators for cancer metastasis $[26,27]$. Here, we investigated the clinical value of different CTCs parameters in the diagnosis of metastasis. In the 25 non-metastatic and 29 metastatic PCa patients, the characteristics of metabolic and EMT phenotypes on CTCs varied among individual patients (Fig. 5a-b and Additional file 11: Table S7). The area under the curves (AUC) of the receiver operating characteristic (ROC) is usually used to evaluate the efficacy of a diagnostic test by taking sensitivity and specificity into account. We therefore simulated the ROC curve to assess the performance of CTCs parameters in discriminating the metastatic PCa patients from the non-metastatic

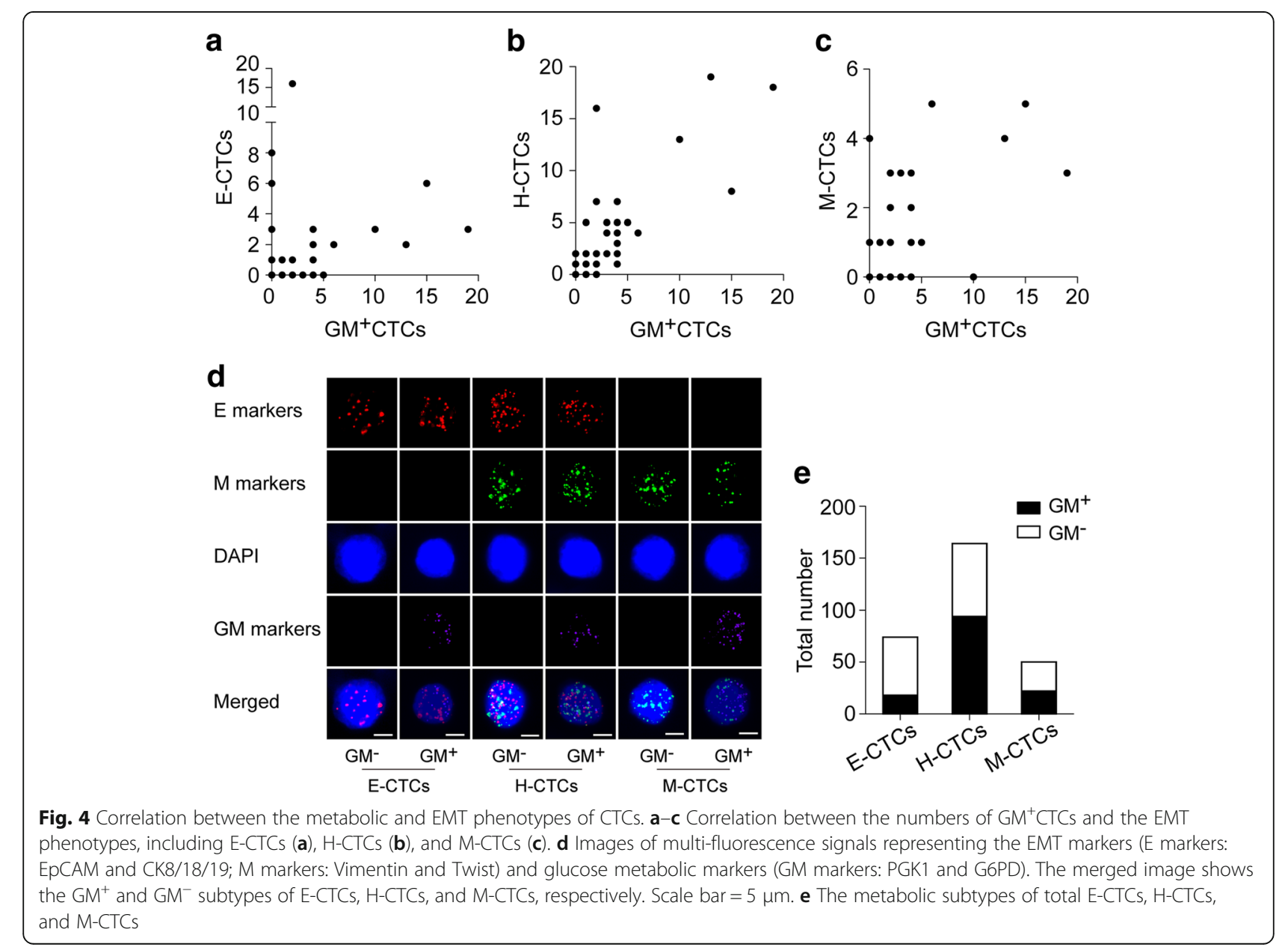



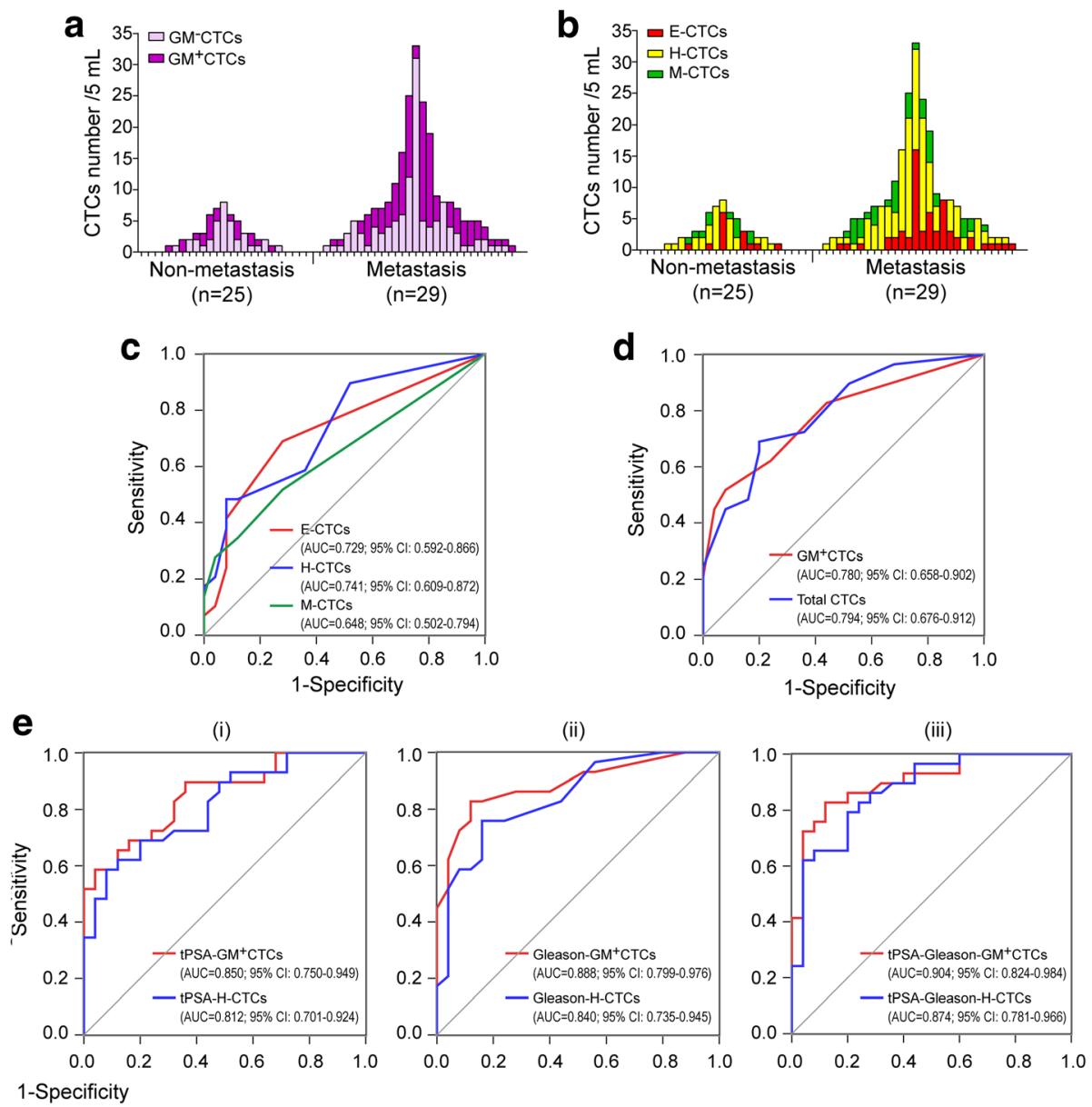

Fig. 5 The performance of the metabolic and EMT subtype CTCs in the diagnosis of tumor metastasis. a Glucose metabolic classification of CTCS in non-metastatic and metastatic patients. $\mathbf{b}$ EMT phenotypes of CTCs in non-metastatic and metastatic patients. c- $\mathbf{d}$ Simulated ROC curves of the CTCs parameters for discriminating the metastatic PCa patients from the non-metastatic patients, including E-CTCs, H-CTCS, and M-CTCS (c), $\mathrm{GM}^{+} \mathrm{CTCs}$ and total CTCS (d). e Simulated ROC curves of the combined bigeminal (i and ii) or trigeminal (iii) markers of $\mathrm{GM}^{+} \mathrm{CTCS}$ and $\mathrm{H}^{-} \mathrm{CTCS}$ for discriminating the metastatic PCa patients from the non-metastatic patients

patients. The AUCs of E-CTCs, H-CTCs, and M-CTCs were $0.729,0.741$, and 0.648 , respectively (Fig. 5 c). The AUC of $\mathrm{GM}^{+} \mathrm{CTCs}$ was 0.780 , which was better than that of the E-, H-, and M-CTCs but similar to that of the total CTCs (0.794) (Fig. 5d). When combining other commonly used clinical indexes, we found that the union of tPSA or Gleason score with the CTCs subtypes $\left(\mathrm{GM}^{+} \mathrm{CTC}\right.$ or $\mathrm{H}$-CTCs) improved the discrimination performance. The AUCs of the combined tPSA- $\mathrm{GM}^{+} \mathrm{CTCs}$ and Gleason$\mathrm{GM}^{+} \mathrm{CTCs}$ markers were 0.850 and 0.888 , which were higher than that of the combined tPSA-H-CTCs (0.812) and Gleason-H-CTCs (0.840) markers (Fig. 5e). A triple tPSA-Gleason-H-CTCs marker presented an AUC of 0.874, whereas the tPSA-Gleason-GM+CTCs marker increased the AUC to 0.904 (95\% CI: 0.855-0.996) (Fig. 5e), with a sensitivity of $82.8 \%$ and specificity of $88.0 \%$. These data demonstrated that the $\mathrm{GM}^{+} \mathrm{CTC}$ s could be potential biomarkers for the diagnosis of tumor metastasis with better performance than EMT-CTCs. A combination of tPSA $>20 \mathrm{ng} / \mathrm{mL}$, Gleason score $\geq$ 8 , and $\mathrm{GM}^{+} \mathrm{CTCs} \geq 3 / 5 \mathrm{~mL}$ provides a high indication of PCa metastasis.

\section{Discussion}

In the present study, we identified the specific metastasis-related metabolic genes and determined PGK1 and G6PD as combined GM markers for the metabolic profiling of CTCs. The GM markers that reflected the metabolic reprogramming could serve as the CTCs biofunctional activity indicators. We also evaluated the clinical significance of the metabolic characterization of CTCs and conducted comparison analysis between the metabolic CTCs phenotypes and the typical CTCs classification using EMT markers. Although the $\mathrm{GM}^{+} \mathrm{CTCs}$ had a correlation with the EMT phenotypes of CTCs, they presented higher AUCs than EMT-CTCs in the discrimination of metastatic 
patients, demonstrating their promise as indicators of $\mathrm{PCa}$ metastasis.

Mitochondrial oxidative phosphorylation is the main energy source for normal cells. Tumor cells, however, depend strongly on the enhanced glycolysis (even in the presence of sufficient oxygen), the pentose phosphate pathway, and glutaminolysis, resulting from the damaged mitochondrial function [11]. This reprogramming of the glucose metabolism plays a vital role in cancer metastasis because it allows tumor cells to escape normal growth processes. The Human Glucose Metabolism Array used in this study is a functional microarray specifically targeting the enzymes and regulators of the glucose and glycogen metabolism. It profiles 84 genes involved in the crucial processes of glycolysis, gluconeogenesis, the tricarboxylic acid cycle, the pentose phosphate pathway, and glycogen synthesis and degradation. The array identified eight metabolic genes differentially expressed among metastatic PCa cell lines: HK2, PDP2, G6PD, PGK1, PHKA1, PYGL, PDK1, and PKM2. The mRNA expressions of these metabolic genes increased significantly in the high metastatic PCa cells (1E8 and DU145) in comparison with the low metastatic cells (2B4, LNCAP, and PC-3). These genes play vital roles in the process of glucose and glycogen metabolism, and studies have demonstrated a remarkable association between their functions and the metastatic capacity of tumor cells [28-33], which was in line with our data. Previous research has found that overexpression of HK2 and PKM2 governs the glucose influx and sustain high levels of glycolysis to promote cancer cell migration and induce stem cell differentiation [28, 29]. PDP2 is the activator of pyruvate dehydrogenase (PDH), and the function of PDH in the cancer-associated fibroblasts was demonstrated essential for the migration ability of the co-cultured cancer cells [30]. PHKA1 and PYGL are regulators of glycogen metabolism which balances the glucose supply. Prakash and his colleges [31] demonstrated that the increased expression of PHKA1 was associated with younger ages of gastrointestinal stromal tumor patients. Hypoxia-induced activation of PYGL resulted in the enhancement of glycogen degradation and further contributed to the in vivo xenograft growth of U87 and MCF-7 cells by optimizing glucose utilization [32]. Kamarajugadda et al. [33] reported that the up-regulated PDKs and $\mathrm{LDH}$ in glycolysis could modulate the estrogen-related receptor gamma (ERRY) to prolong the survival of mammary epithelial cells that break away from the matrix. This process strengthened the anoikis resistance to promote cell invasion and migration. These studies suggested the array-selected genes could be potential metabolic markers related to cancer metastasis.

Notably, in the verification assays, we observed inconsistent results between the protein and mRNA levels of HK2, PDP2, G6PD, PYGL, and PKM2 in the comparison of the 2B4 cells and 1E8 cells. Earlier studies reported the inconsistency between the protein and mRNA levels of gene expression in human tissue and cells [34, 35], which did not conform to the Central Dogma of biological genetics. The reasons for this phenomenon might be biological and technological. Biologically, the complicated post-transcriptional and translational regulations, such as alternative splicing [36], non-coding RNAs (miRNA and siRNA) interference [37, 38], and translational recoding [39] could change the protein level of the transcribed mRNA. Technologically, the characteristics of current methods might decrease the accuracy of mRNA or protein quantification. For instance, if an important splice variation or translational modification occurs in gene expression, the use of monoclonal antibodies directed to the wild-type could result in different protein information from mRNA expression $[40,41]$. Further systematic experiments are needed to explore the concrete mechanism of the specific genes identified in the present study.

The AHP is one of the most widely used methods of multi-criteria decision analysis [24, 25]. It structures complex decision problems into a hierarchical system to conduct a rational and practical decision-making [42]. We found that the mRNA expression of the metabolic genes varied among individual CTCs of blood samples, which revealed that the changes in tumor cell lines might not be exactly the same as those in the peripheral CTCs because of the difference in sample types and detecting techniques. Thus, we used the AHP-based multi-criteria weighted model by which PGK1 and G6PD were determined as the optimal markers for CTCs metabolic analysis. They function as key enzymes in glycolysis and the pentose phosphate pathway, respectively. PGK1 catalyzes 1,3-diphosphoglyceric acid to generate 3-phosphoglyceric acid and ATP. G6PD catalyzes the dehydrogenation of glucose 6-phosphate to generate ribulose-5-phosphate and further produce ribose 5-phosphate and NADPH. Experimental and clinical studies have demonstrated the pivotal role of PGK1 and G6PD in cell malignance and cancer metastasis [43-50]. A mouse model study of metastatic gastric cancer demonstrated that the overexpression of PGK1 significantly increased the invasive and metastatic behavior of the implanted gastric tumors [43]. Apart from the PGK1-induced enhancement of energy supply, the mechanism might involve the stimulation of PGK1-activated oncogenic AKT/mTOR pathway in tumor cells [44]. Studies by Ahmad et al. [45] and Xie et al. [46] revealed that the PGK1 expression was up-regulated in the tissue of metastatic colon cancer and was closely correlated to the poor prognosis of hepatocellular carcinoma patients. Kowalik et al. [47] used a rat model to identify the most aggressive lesions at early phases of hepatic carcinogenesis 
and found that the increased G6PD expression induced aggressive preneoplastic hepatocytes. G6PD could activate the STAT3 pathway to induce the EMT process and further promote the migration and invasion of hepatocellular carcinoma cells [48]. The clinical analysis also revealed that the G6PD level is associated with high risk of recurrence and poor survival in patients with gastric [49] and renal [50] cancers. Therefore, increased activity of glycolysis and the pentose phosphate pathway (indicated by the up-regulation of PGK1 and G6PD) might reflect the active status of glucose metabolism in CTCs, which further reveals CTCs aggressiveness.

This theory was confirmed by the metabolic analysis of peripheral CTCs in PCa patients. The results demonstrated that the $\mathrm{GM}^{+} \mathrm{CTCs}$ marked by PGK1 and G6PD were closely associated with the patients' clinical stage, cancer metastasis and serum tPSA level, although they made up only a small part of the total CTCs. A high baseline of total CTCs has proved relevant to the metastatic tendency and decreased survival of PCa [51, 52], whereas the reports on the associations between total CTCs and the clinical stage or serum tPSA are not exactly the same. For example, Resel et al. [53] demonstrated a positive correlation between the CTCs count and disease stage or tPSA level. On the contrary, research by Oscar et al. [51] and Tsumura et al. [54] suggested that the clinical stage and PSA level at diagnosis had no correlation with the baseline number of CTCs. The different detection methods used in these studies and the heterogeneity of CTCs population might explain the discrepancy. Here, we found that the positive rate and number of $\mathrm{GM}^{+} \mathrm{CTCs}$ were remarkably correlated with tumor stage and tPSA level. $\mathrm{GM}^{+} \mathrm{CTCs} \geq 3 / 5 \mathrm{~mL}$ was indicative of the advanced tumor stage and increased tPSA concentration, which were both significant prognostic biomarkers for $\mathrm{PCa}$ patients. These data suggest that the $\mathrm{GM}^{+} \mathrm{CTCs}$, as a highly aggressive subpopulation of the total CTCs, might be a more precise marker for tumor malignance and progression.

The EMT phenotype of CTCs is currently the most common indicator of cancer metastasis and prognosis $[55,56]$. Previous reports proved the vital role of metabolic genes in EMT by in vivo and in vitro experiments. Wu et al. [57] investigated the effect of G6PD knockdown on A549, MDCK cells, and zebrafish embryos. They observed morphological changes and suppression of epithelial markers such as E-cadherin. A subcellular localization study found that the nuclear translocation of PKM2 regulated the EGF-induced EMT by promoting the transactivation of $\beta$-catenin [58]. In return, EMT can reprogram the cancer metabolic profile by activating transcription factors. Twist is a well-known transcription factor of EMT. A Twist-overexpressing assay in breast cancer cells demonstrated the up-regulation of metabolic enzymes such as LDHA, PKM2, HK2, and G6PD, which was mediated by the PI3K/AKT and p53 signaling pathways [59]. Therefore, the metabolic reprogramming and EMT, which are both crucial for the biological behavior of tumor cells, can mutually regulate each other and synergistically promote cancer metastasis. Here, our work found that the $\mathrm{H}$-CTCs and M-CTCs presented higher $\mathrm{GM}^{+} \mathrm{CTCs}$ proportions and $\mathrm{GM}^{+} \mathrm{CTCs}$ correlation coefficients than those in the E-CTCs. This result also verified the significant interrelation between the metabolic and EMT phenotypes of CTCs.

Recent studies on gastric [10], colorectal [26] and breast [27] cancers demonstrated that M-CTCs rather than E-CTCs were more relevant to tumor progression and metastasis. Nonetheless, inconsistent with these reports, our results revealed that the H-CTCs but not E-CTCs or M-CTCs were significantly correlated with the metastasis of PCa. This case has two possible explanations. On the one hand, EMT is dynamic, and the reversible EMT-MET occurred during the dissemination and metastasis of tumor cells [60]. This phenomenon might result in the diversity of cell biological activities and functions even though they present the same morphological EMT phenotype. On the other hand, the importance of epithelial plasticity to metastasis has recently attracted considerable attention. A study by Ruscetti et al. [61] found that although mesenchymal and hybrid CTCs increased tumorigenesis in transgenic mouse models, only hybrid and epithelial CTCs formed macro-metastases, whereas mesenchymal CTCs persisted as micro-metastatic foci. In fact, hybrid CTCs may represent the most plastic tumor cells because they have both the epithelial and mesenchymal plasticity [62]. Therefore, the hybrid CTCs might have the greatest potential to contribute to cancer metastasis. Our next investigations showed that the $\mathrm{GM}^{+} \mathrm{CTCs}$ number was closely correlated with the number of H-CTCs $(r=0.807)$, whereas correlations between $\mathrm{GM}^{+} \mathrm{CTCs}$ and E-CTCs $(r=$ $0.369)$ or M-CTCs $(r=0.553)$ were moderate. These data also supported the highlighted significance of hybrid CTCs in cancer metastasis. Besides, the metabolic analysis of CTCs provides a way to help settle the controversial outcomes of EMT subtypes. The aggressiveness of malignant cells might depend more on the metabolic activity as a functional indicator, compared with the morphological EMT features. We used the simulated ROC to assess the performance of EMT-CTCs and $\mathrm{GM}^{+} \mathrm{CTCs}$ in the discrimination of metastatic PCa patients. The AUCs of $\mathrm{GM}^{+} \mathrm{CTCs}$ were higher than that of H-CTCs, no matter as a single marker or as combined markers with tPSA and the Gleason score. These results demonstrate that the hypermetabolic CTCs could be a more accurate marker than EMT-CTCs for revealing the metastasis and disease progression of cancer patients.

In addition, the multi-RNA-ISH technique used in this method not only offers sensitive and visualized detection 
of the metabolic markers, but could also facilitate the integrated CTCs characterization with the combination of EMT phenotypes. Simultaneously profiling the metabolic and EMT subtypes would improve the molecular analysis of CTCs from the functional and morphological aspects, and further contribute to the understanding of tumor transfer mechanism and better application of CTCs tests. Nevertheless, some additional experiments are necessary to perfect this study. In the aspect of the fundamental theory, the biological functions of the PGK1/G6PD-positive CTCs and the related mechanisms remain to be illustrated using in vitro culture assays. In terms of research methodology, new techniques for the protein detection of the metabolic markers in CTCs need to be developed and tested for clinical applications. Moreover, an expanded sample size of $\mathrm{PCa}$ and other carcinomas would also be helpful to confirm the clinical significance of this method. Follow-up investigations on the prognostic and monitoring roles of specific metabolic CTCs phenotype will be conducted in the future.

\section{Conclusions}

This work identifies the metabolic markers (PGK1/G6PD) as the biofunctional activity indicator for CTCs. On the basis of the existing morphological (EMT) classification of CTCs, we have established a metabolic characterization method and evaluated the clinical significance in PCa patients. The PGK1/G6PD-marked hypermetabolic CTCs $\left(\mathrm{GM}^{+} \mathrm{CTCs}\right)$ are promising biomarkers for the diagnosis of cancer metastasis. A combination of tPSA $>20 \mathrm{ng} / \mathrm{mL}$, Gleason score $\geq 8$, and $\mathrm{GM}^{+} \mathrm{CTCs} \geq 3 / 5 \mathrm{~mL}$ provides a high indication of $\mathrm{PCa}$ metastasis, with a sensitivity of $82.8 \%$ and specificity of $88.0 \%$.

\section{Additional files}

Additional file 1: Table S1. Primer sequences for qRT-PCR. (DOCX $20 \mathrm{~kb}$ ) Additional file 2: Table S2. Antibodies used in Western blot analysis. (DOCX $21 \mathrm{~kb})$

Additional file 3: Determination of the positive standard for CTCS counting. (DOCX $133 \mathrm{~kb}$ )

Additional file 4: Table S3. Capture probes of the glucose metabolism genes used in the RNA-ISH. (DOCX $21 \mathrm{~kb}$ )

Additional file 5: Figure S1. Migration and invasion assays of the five PCa cell lines. (A-B) Representative images and statistical comparison between PC-3 M 2B4 and PC-3 M 1E8 cells in wound healing $(A, 100 x)$ and Transwell $(B, 200 x)$ assays. (C-D) Representative images and statistical comparison among LNCAP, PC-3, and DU145 cells by wound healing $(C, 100 \times)$ and Transwell $(\mathrm{D}, 200 \mathrm{X})$ assays. ${ }^{* * * *} \mathrm{P}<0.001$; Scale bar $=150 \mu \mathrm{m}$. (TIF $\left.19013 \mathrm{~kb}\right)$

Additional file 6: Table S4. Gene information on the Human Glucose Metabolism Array. (DOCX $19 \mathrm{~kb}$ )

Additional file 7: Figure S2. Functions of the differentially expressed genes in glucose and glycogen metabolism. These genes included HK2, PDP2, G6PD, PGK1, PHKA1, PYGL, PDK1, and PKM2. (TIF $1108 \mathrm{~kb}$ )

Additional file 8: Figure S3. The pairwise comparison matrix used in the AHP model. The weighting coefficients of the criteria layer were calculated on the basis of the maximum eigenvalue using the sumproduct method. (TIF $481 \mathrm{~kb}$ )

Additional file 9: Table S5. Weighted scores of the metabolic gene candidates calculated by the AHP-based model. (DOCX $20 \mathrm{~kb}$ )

Additional file 10: Table S6. Correlation between the EMT phenotypes of CTCs and clinical characteristics of PCa patients (Cohort 2). (DOCX $24 \mathrm{~kb}$ )

Additional file 11: Table S7. Metabolic and EMT subtypes of CTCs in non-metastatic and metastatic PCa patients (Cohort 2). (DOCX 24 kb)

\section{Abbreviations}

AHP: Analytic hierarchy process; ALP: Alkaline phosphatase; AUC: Area under the curve; CTCs: Circulating tumor cells; EMT: Epithelial-mesenchymal transition; G6PD: Glucose-6-phosphate dehydrogenase; Hb: Hemoglobin B; MET: Mesenchymal-epithelial transition; PCa: Prostate cancer;

PGK1: Phosphoglycerate kinase 1; qRT-PCR: Quantitative real-time polymerase chain reaction; RNA-ISH: RNA in situ hybridization; ROC: Receiver operating characteristic; tPSA: Total prostate-specific antigen

\section{Acknowledgments}

We thank Qiang Wei and Peng Wu (Urology Department, Nanfang Hospital, Southern Medical University), as well as Bin-shen Chen and Yi-ming Zhang (Urology Department, Zhujiang Hospital, Southern Medical University), for their clinical guidance.

\section{Consent of publication \\ Not applicable.}

\section{Funding}

This work is supported by Guangdong Natural Science Foundation, China (No. 2015A030313247), Guangdong Science and Technology Planning Project, China (No. 2016A010105006), and Nanning Science and Technology Planning Project, China (No. 20163335).

\section{Availability of data and materials}

All data generated or analyzed during this study are included in this article and its supplementary information files.

\section{Authors' contributions}

QW, LZ, ZC, and JC conceived and designed the research. Cell experiments were conducted by JC, SC, YH, JH, and JL. Blood sample collection and detection were performed by JC, BS, JZ, SL, JX, SW, and QZ. Data analysis and manuscript preparation were handled by JC, SC, ZC, and LZ. All authors approved the final version of the manuscript.

Ethics approval and consent to participate

A declaration on the ethics approval and patient consent has been stated in the Methods part.

\section{Competing interests}

The authors declare that they have no competing interests.

\section{Publisher's Note}

Springer Nature remains neutral with regard to jurisdictional claims in published maps and institutional affiliations.

\footnotetext{
Author details

'Laboratory Medicine Center, Nanfang Hospital, Southern Medical University, 1838 North of Guangzhou Avenue, Guangzhou 510515, Guangdong, China. ${ }^{2}$ Guangdong Engineering and Technology Research Center for Rapid Diagnostic Biosensors, Nanfang Hospital, Southern Medical University, Guangzhou, Guangdong, China. ${ }^{3}$ Department of Traditional Chinese Medicine, The First People's Hospital of Nanning, Nanning, Guangxi, China. ${ }^{4}$ Department of Clinical Laboratory, First Affiliated Hospital of Fujian Medical University, Fuzhou, Fujian, China. ${ }^{5}$ SurExam Bio-Tech, Guangzhou Technology Innovation Base, Science City, Guangzhou, Guangdong, China. ${ }^{6}$ Zhujiang Hospital, Southern Medical University, Guangzhou, Guangdong, China.
} 


\section{Received: 7 March 2018 Accepted: 12 June 2018}

Published online: 28 June 2018

\section{References}

1. Hodgkinson CL, Morrow CJ, Li Y, Metcalf RL, Rothwell DG, Trapani F, Polanski R, Burt DJ, Simpson KL, Morris K, et al. Tumorigenicity and genetic profiling of circulating tumor cells in small-cell lung cancer. Nat Med. 2014 20(8):897-903.

2. Williams ES, Rodriguez-Bravo V, Chippada-Venkata U, De la Iglesia-Vicente J, Gong Y, Galsky M, Oh W, Cordon-Cardo C, Domingo-Domenech J. Generation of prostate Cancer patient derived xenograft models from circulating tumor cells. J Vis Exp. 2015;105:53182.

3. Cabel L, Proudhon C, Gortais H, Loirat D, Coussy F, Pierga JY, Bidard FC. Circulating tumor cells: clinical validity and utility. Int J Clin Oncol. 2017; 22(3):421-30.

4. Liu M, Tang M, Li M, Gao F, Shi C, Hou J, Zeng W. Circulating tumor cells: a new window for diagnosis and evaluation of Cancer. Anti Cancer Agents Med Chem. 2016;16(12):1529-40.

5. Alix-Panabieres C, Pantel K. Clinical applications of circulating tumor cells and circulating tumor DNA as liquid biopsy. Cancer Discov. 2016;6(5):479-91.

6. Michor F, Polyak K. The origins and implications of intratumor heterogeneity. Cancer Prev Res (Phila). 2010;3(11):1361-4.

7. Visvader JE. Cells of origin in cancer. Nature. 2011;469(7330):314-22.

8. Thiery JP. Epithelial-mesenchymal transitions in tumour progression. Nat Rev Cancer. 2002;2(6):442-54.

9. Yu M, Bardia A, Wittner BS, Stott SL, Smas ME, Ting DT, Isakoff SJ, Ciciliano JC, Wells MN, Shah AM, et al. Circulating breast tumor cells exhibit dynamic changes in epithelial and mesenchymal composition. Science. 2013; 339(6119):580-4.

10. Li TT, Liu H, Li FP, Hu YF, Mou TY, Lin T, Yu J, Zheng L, Li GX. Evaluation of epithelial-mesenchymal transitioned circulating tumor cells in patients with resectable gastric cancer: relevance to therapy response. World J Gastroenterol. 2015;21(47):13259-67.

11. Hanahan D, Weinberg RA. Hallmarks of cancer: the next generation. Cell. 2011;144(5):646-74.

12. Cuyas E, Corominas-Faja B, Menendez JA. The nutritional phenome of EMTinduced cancer stem-like cells. Oncotarget. 2014:5(12):3970-82.

13. Weber GF. Metabolism in cancer metastasis. Int J Cancer. 2016;138(9):2061-6.

14. Weber GF. Time and circumstances: Cancer cell metabolism at various stages of disease progression. Front Oncol. 2016;6:257.

15. Cai Z, Zhou Y, Lei T, Chiu JF, He QY. Mammary serine protease inhibitor inhibits epithelial growth factor-induced epithelial-mesenchymal transition of esophageal carcinoma cells. Cancer. 2009;115(1):36-48.

16. Bettum IJ, Gorad SS, Barkovskaya A, Pettersen S, Moestue SA, Vasiliauskaite K, Tenstad E, Oyjord T, Risa O, Nygaard V, et al. Metabolic reprogramming supports the invasive phenotype in malignant melanoma. Cancer Lett. 2015; 366(1):71-83.

17. Zhao J, Li J, Fan TWM, Hou SX. Glycolytic reprogramming through PCK2 regulates tumor initiation of prostate cancer cells. Oncotarget. 2017;8(48): 83602-18.

18. Livak KJ, Schmittgen TD. Analysis of relative gene expression data using real-time quantitative $P C R$ and the 2(-Delta Delta $C(T)$ ) method. Methods. 2001:25(4):402-8

19. Wu S, Liu S, Liu Z, Huang J, Pu X, Li J, Yang D, Deng H, Yang N, Xu J. Classification of circulating tumor cells by epithelial-mesenchymal transition markers. PLoS One. 2015;10(4):e0123976.

20. Liu Y, Zheng J, Fang W, You J, Wang J, Cui X, Wu B. Isolation and characterization of human prostate cancer cell subclones with different metastatic potential. Zhonghua Bing Li Xue Za Zhi. 1999;28(5):361-4.

21. Horoszewicz JS, Leong SS, Chu TM, Wajsman ZL, Friedman M, Papsidero L, Kim U. Chai LS, Kakati S, Arya SK, et al. The LNCaP cell line-a new model for studies on human prostatic carcinoma. Prog Clin Biol Res. 1980;37:115-32.

22. Kaighn ME, Narayan KS, Ohnuki Y, Lechner JF, Jones LW. Establishment and characterization of a human prostatic carcinoma cell line (PC-3). Investig Urol. 1979;17(1):16-23.

23. Stone KR, Mickey DD, Wunderli H, Mickey GH, Paulson DF. Isolation of a human prostate carcinoma cell line (DU 145). Int J Cancer. 1978;21(3):274-81.

24. Saaty TL. A scaling method for priorities in hierarchical structures. J Math Psychol. 1977;15(3):234-81.

25. Saaty RW. The analytic hierarchy process - what it is and how it is used. Mathematical Modelling. 1987;9(3):161-76.
26. Zhao R, Cai Z, Li S, Cheng Y, Gao H, Liu F, Wu S, Liu S, Dong Y, Zheng L, et al. Expression and clinical relevance of epithelial and mesenchymal markers in circulating tumor cells from colorectal cancer. Oncotarget. 2017;8(6): 9293-302.

27. Li S, Chen Q, Li H, Wu Y, Feng J, Yan Y. Mesenchymal circulating tumor cells (CTCs) and OCT4 mRNA expression in CTCs for prognosis prediction in patients with non-small-cell lung cancer. Clin Transl Oncol. 2017;19(9):1147-53.

28. Yang P, Li Z, Fu R, Wu H, Li Z. Pyruvate kinase M2 facilitates colon cancer cell migration via the modulation of STAT3 signalling. Cell Signal. 2014;26(9):1853-62

29. Kim H, Jang H, Kim TW, Kang BH, Lee SE, Jeon YK, Chung DH, Choi J, Shin J, Cho EJ, et al. Core pluripotency factors directly regulate metabolism in embryonic stem cell to maintain pluripotency. Stem Cells. 2015;33(9):2699-711.

30. Koukourakis MI, Kalamida D, Mitrakas AG, Liousia M, Pouliliou S, Sivridis E, Giatromanolaki A. Metabolic cooperation between co-cultured lung cancer cells and lung fibroblasts. Lab Investig. 2017:97(11):1321-31.

31. Prakash S, Sarran L, Socci N, DeMatteo RP, Eisenstat J, Greco AM, Maki RG, Wexler LH, LaQuaglia MP, Besmer P, et al. Gastrointestinal stromal tumors in children and young adults: a clinicopathologic, molecular, and genomic study of 15 cases and review of the literature. J Pediatr Hematol Oncol. 2005;27(4):179-87

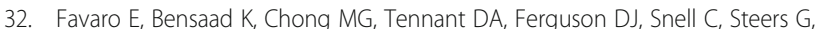
Turley H, Li JL, Günther UL, et al. Glucose utilization via glycogen phosphorylase sustains proliferation and prevents premature senescence in cancer cells. Cell Metab. 2012;16(6):751-64.

33. Kamarajugadda S, Stemboroski L, Cai Q, Simpson NE, Nayak S, Tan M, Lu J. Glucose oxidation modulates anoikis and tumor metastasis. Mol Cell Biol. 2012;32(10):1893-907.

34. Chen G, Gharib TG, Huang CC, Taylor JM, Misek DE, Kardia SL, Giordano TJ, lannettoni MD, Orringer MB, Hanash SM, et al. Discordant protein and mRNA expression in lung adenocarcinomas. Mol Cell Proteomics. 2002;1 (4):304-13.

35. Guo Y, Xiao P, Lei S, Deng F, Xiao GG, Liu Y, Chen X, Li L, Wu S, Chen Y, et al. How is mRNA expression predictive for protein expression? A correlation study on human circulating monocytes. Acta Biochim Biophys Sin Shanghai. 2008:40(5):426-36.

36. Hu J, Zhao W, Zhan S, Xiao P, Zhou J, Wang L, Li L, Zhang H, Niu L, Zhong T. Delta-like 1 homolog in Capra hircus: molecular characteristics, expression pattern and phylogeny. Mol Biol Rep. 2016;43(6):563-71.

37. Wei J, Ma Z, Li Y, Zhao B, Wang D, Jin $Y$, Jin Y. MiR-143 inhibits cell proliferation by targeting autophagy-related $2 \mathrm{~B}$ in non-small cell lung cancer H1299 cells. Mol Med Rep. 2015;11(1):571-6.

38. Kaucsár T, Rácz Z, Hamar P. Post-transcriptional gene-expression regulation by micro RNA (miRNA) network in renal disease. Adv Drug Deliv Rev. 2010; 62(14):1390-401

39. Dinman JD. Control of gene expression by translational recoding. Adv Protein Chem Struct Biol. 2012:86:129-49.

40. O'Neill PA, Davies MP, Shaaban AM, Innes H, Torevell A, Sibson DR, Foster CS. Wild-type oestrogen receptor beta (ERb1) mRNA and protein expression in tamoxifen-treated post-menopausal breast cancers. Br J Cancer. 2004;91: 1694-702.

41. Vorobyov E, Horst J. Expression of two protein isoforms of PAX7 is controlled by competing cleavage-polyadenylation and splicing. Gene. 2004;342(1):107-12.

42. Ho W. Integrated analytic hierarchy process and its applications - a literature review. Eur J Oper Res. 2008;186(1):211-28.

43. Zieker D, Konigsrainer I, Weinreich J, Beckert S, Glatzle J, Nieselt K, Buhler S, Loffler M, Gaedcke J, Northoff H, et al. Phosphoglycerate kinase 1 promoting tumor progression and metastasis in gastric cancer - detected in a tumor mouse model using positron emission tomography/magnetic resonance imaging. Cell Physiol Biochem. 2010:26(2):147-54.

44. Yu T, Zhao Y, Hu Z, Li J, Chu D, Zhang J, Li Z, Chen B, Zhang X, Pan H, et al. MetaLnc9 facilitates lung Cancer metastasis via a PGK1-activated AKT/mTOR pathway. Cancer Res. 2017;77(21):5782-94.

45. Ahmad SS, Glatzle J, Bajaeifer K, Buhler S, Lehmann T, Konigsrainer I, Vollmer JP, Sipos B, Ahmad SS, Northoff H, et al. Phosphoglycerate kinase 1 as a promoter of metastasis in colon cancer. Int J Oncol. 2013;43(2):586-90.

46. Xie $H_{\text {, Tong }} \mathrm{G}$, Zhang $Y$, Liang $\mathrm{S}$, Tang $\mathrm{K}$, Yang Q. PGK1 drives hepatocellular carcinoma metastasis by enhancing metabolic process. Int J Mol Sci. 2017;18:8.

47. Kowalik MA, Guzzo G, Morandi A, Perra A, Menegon S, Masgras I, Trevisan E, Angioni MM, Fornari F, Quagliata L, et al. Metabolic reprogramming identifies the most aggressive lesions at early phases of hepatic carcinogenesis. Oncotarget. 2016;7(22):32375-93. 
48. Lu M, Lu L, Dong Q, Yu G, Chen J, Qin L, Wang L, Zhu W, Jia H. Elevated G6PD expression contributes to migration and invasion of hepatocellular carcinoma cells by inducing epithelial-mesenchymal transition. Acta Biochim Biophys Sin Shanghai. 2018;50(4):370-80.

49. Wang J, Yuan W, Chen Z, Wu S, Chen J, Ge J, Hou F, Chen Z. Overexpression of G6PD is associated with poor clinical outcome in gastric cancer. Tumour Biol. 2012;33(1):95-101.

50. Zhang $Q$, Yi X, Yang Z, Han Q, Di X, Chen F, Wang Y, Yi Z, Kuang Y, Zhu Y. Overexpression of G6PD represents a potential prognostic factor in clear cell renal cell carcinoma. J Cancer. 2017;8(4):665-73.

51. Goodman OB Jr, Fink LM, Symanowski JT, Wong B, Grobaski B, Pomerantz $D, M a$ Y, Ward DC, Vogelzang NJ. Circulating tumor cells in patients with castration-resistant prostate cancer baseline values and correlation with prognostic factors. Cancer Epidemiol Biomark Prev. 2009;18(6):1904-13.

52. Moreno JG, Miller MC, Gross S, Allard WJ, Gomella LG, Terstappen LW. Circulating tumor cells predict survival in patients with metastatic prostate cancer. Urology. 2005;65(4):713-8.

53. Resel Folkersma L, Olivier Gomez C, San Jose Manso L, Veganzones de Castro S, Galante Romo I, Vidaurreta Lazaro M, de la Orden GV, Arroyo Fernandez M, Diaz Rubio E, Silmi Moyano A, et al. Immunomagnetic quantification of circulating tumoral cells in patients with prostate cancer: clinical and pathological correlation. Arch Esp Urol. 2010;63(1):23-31.

54. Tsumura H, Satoh T, Ishiyama H, Tabata Kl, Takenaka K, Sekiguchi A, Nakamura M, Kitano M, Hayakawa K, Iwamura M. Perioperative search for circulating tumor cells in patients undergoing prostate brachytherapy for clinically nonmetastatic prostate Cancer. Int J Mol Sci. 2017:18(1):E128.

55. Garg M. Epithelial, mesenchymal and hybrid epithelial/mesenchymal phenotypes and their clinical relevance in cancer metastasis. Expert Rev Mol Med. 2017;19:e3.

56. Bhatia S, Monkman J, Toh AKL, Nagaraj SH, Thompson EW. Targeting epithelial-mesenchymal plasticity in cancer: clinical and preclinical advances in therapy and monitoring. Biochem J. 2017;474(19):3269-306.

57. Wu YH, Lee YH, Shih HY, Chen SH, Cheng YC, Tsun-Yee Chiu D. Glucose-6phosphate dehydrogenase is indispensable in embryonic development by modulation of epithelial-mesenchymal transition via the NOX/Smad3/miR200b axis. Cell Death Dis. 2018;9(1):10.

58. Yang W, Xia Y, Ji H, Zheng Y, Liang J, Huang W, Gao X, Aldape K, Lu Z Nuclear PKM2 regulates beta-catenin transactivation upon EGFR activation. Nature. 2011;480(7375):118-22.

59. Yang L, Hou Y, Yuan J, Tang S, Zhang H, Zhu Q, Du YE, Zhou M, Wen S, Xu $L$, et al. Twist promotes reprogramming of glucose metabolism in breas cancer cells through PI3K/AKT and p53 signaling pathways. Oncotarget. 2015;6(28):25755-69.

60. Jolly MK, Ware KE, Gilja S, Somarelli JA, Levine H. EMT and MET: necessary or permissive for metastasis ? Mol Oncol. 2017;11(7):755-69.

61. Ruscetti M, Quach B, Dadashian EL, Mulholland DJ, Wu H. Tracking and functional characterization of epithelial-mesenchymal transition and mesenchymal tumor cells during prostate Cancer metastasis. Cancer Res. 2015;75(13):2749-59.

62. Jolly MK, Boareto M, Huang B, Jia D, Lu M, Ben-Jacob E, Onuchic JN, Levine H. Implications of the hybrid epithelial/mesenchymal phenotype in metastasis. Front Oncol. 2015;5:155.

\section{Ready to submit your research? Choose BMC and benefit from:}

- fast, convenient online submission

- thorough peer review by experienced researchers in your field

- rapid publication on acceptance

- support for research data, including large and complex data types

- gold Open Access which fosters wider collaboration and increased citations

- maximum visibility for your research: over $100 \mathrm{M}$ website views per year

At BMC, research is always in progress.

Learn more biomedcentral.com/submissions 